\title{
Disability in long-term care residents explained by prevalent geriatric syndromes, not long-term care home characteristics: a cross-sectional study
}

\author{
Natasha E. Lane ${ }^{1 *}$, Walter P. Wodchis ${ }^{1,2,3}$, Cynthia M. Boyd $d^{4,5,6}$ and Thérèse A. Stukel ${ }^{2,1,7}$
}

\begin{abstract}
Background: Self-care disability is dependence on others to conduct activities of daily living, such as bathing, eating and dressing. Among long-term care residents, self-care disability lowers quality of life and increases health care costs. Understanding the correlates of self-care disability in this population is critical to guide clinical care and ongoing research in Geriatrics. This study examines which resident geriatric syndromes and chronic conditions are associated with residents' self-care disability and whether these relationships vary across strata of age, sex and cognitive status. It also describes the proportion of variance in residents' self-care disability that is explained by residents' geriatric syndromes versus long-term care home characteristics.
\end{abstract}

Methods: We conducted a cross-sectional study using a health administrative cohort of 77,165 long-term care home residents residing in 614 Ontario long-term care homes. Eligible residents had their self-care disability assessed using the RAI-MDS 2.0 activities of daily living long-form score (range: 0-28) within 90 days of April 1st, 2011. Hierarchical multivariable regression models with random effects for long-term care homes were used to estimate the association between self-care disability and resident geriatric syndromes, chronic conditions and long-term care home characteristics. Differences in findings across strata of sex, age and cognitive status (cognitively intact versus cognitively impaired) were examined.

Results: Geriatric syndromes were much more strongly associated with self-care disability than chronic conditions in multivariable models. The direction and size of some of these effects were different for cognitively impaired versus cognitively intact residents. Residents' geriatric syndromes explained $50 \%$ of the variation in their selfcare disability scores, while characteristics of long-term care homes explained an additional 2\% of variation.

Conclusion: Differences in long-term care residents' self-care disability are largely explained by prevalent geriatric syndromes. After adjusting for resident characteristics, there is little variation in self-care disability associated with long-term care home characteristics. This suggests that residents' geriatric syndromes-not the homes in which they live-may be the appropriate target of interventions to reduce self-care disability, and that such interventions may need to differ for cognitively impaired versus unimpaired residents.

Keywords: Activities of daily living, Chronic disease, Disability, Disablement Process, Geriatric syndrome, Nursing homes

\footnotetext{
* Correspondence: natasha.lane@mail.utoronto.ca

${ }^{1}$ Institute of Health Policy, Management and Evaluation, University of

Toronto, 155 College St, 4th Floor, Toronto, ON M5T 3M6, Canada

Full list of author information is available at the end of the article
} 


\section{Background}

Long-term care homes (LTCHs) are publicly-funded facilities for older adults whose care needs are greater than the level provided by home care or retirement homes, but less than that provided in hospital [1]. Demand for institutional long-term care is increasing globally, as are the acuity and complexity of LTCH (or "nursing home") residents [2]. Most LTCH residents have some self-care disability, defined as difficulty with or dependence on others to conduct activities of daily living (ADLs), such as bathing, eating and dressing [1]. Self-care disability (henceforth "disability") tends to increase over time among LTCH residents [3] and is associated with lower self-rated quality of life [4], repeat hospitalizations [5], higher health care utilization [6] and all-cause mortality [7, 8]. Based on its association with these important resident outcomes, resident disability measures are included in pay-for-performance schemes and publicly reported LTCH quality metrics in jurisdictions across North America [9-11].

There is limited evidence regarding the association of specific resident and $\mathrm{LTCH}$ characteristics with resident disability [12], or the extent that these associations differ by age [13], sex [14] and cognitive status [15]. Identifying the resident or LTCH characteristics that explain differences in resident disability could guide targeting of clinical interventions to prevent or slow its onset. Determining whether the effects of geriatric syndromes and chronic conditions on disability differ by age, sex and cognitive status is important because imbalanced effect modifiers in research samples skew findings. Existing studies of these relationships are limited by small or single-sex samples, inadequate control for confounders, lack of adjustment for clustering of residents within LTCHs, and selection bias due to voluntary LTCH participation [16-19].

We conducted a cross-sectional administrative data study to answer the following questions and fill these evidence gaps:

1. Which resident geriatric syndromes and chronic conditions are most strongly associated with disability in LTCH residents?

2. Are these relationships moderated by residents' sex, age or cognitive status?

3. What is the proportion of variance in resident disability explained by resident characteristics versus LTCH characteristics?

Our examination of these questions was guided by Verbrugge and Jette's Disablement Process Model [20]. The Disablement Process Model is a theoretical framework that outlines a pathway through which pathologies lead to impairments, which give way to limitations in functional capacity [20]. Reduced functional capacity then interacts with individuals' sociodemographic characteristics and context to cause disability [20]. Additional file 1: Table S1 contains definitions and examples for pathology, impairment, functional limitation, sociodemographic ("intra-individual") characteristics and contextual ("extra-individual") factors from Verbrugge and Jette's Disablement Process Model paper [20]. There was an additional "risk factors" construct in the original Disablement Process Model, however because all of the risk factors were also sociodemographic characteristics these categories were collapsed in this study.

We incorporated this framework into this study in two ways. First, our variable selection and model specification were based on constructs in the Disablement Process Model. The "chronic pathologies" construct was represented by chronic conditions - such as heart failure or Parkinson's disease-defined as "illnesses lasting six months or more, including past illnesses requiring continuous care, diseases with risk of recurrence or previous health problems that continue to affect health management" [21]. The "impairments" construct was represented by geriatric syndromes,-such as balance impairment or urinary incontinence-defined as "a collection of signs and symptoms common in older residents but not necessarily fitting into discrete disease categories" [22]. Second, we tested an extension of the original model to see whether there is effect modification of exposure-disability relationships by resident age, sex and cognitive status. We hypothesized that the effects of chronic diseases and geriatric syndromes on disability would be stronger among women, the oldest old and individuals who were cognitively impaired.

\section{Methods}

We enrolled all LTCH residents in Ontario, Canada, whose disability was assessed within 90 days $(+/-)$ of the index date, April 1, 2011. We then applied several exclusions (Fig. 1) and used residents' de-identified and encrypted provincial health insurance numbers to link health administrative databases housed at the Institute for Clinical Evaluative Sciences (ICES).

\section{Data sources}

Resident records were linked using unique, anonymized, encrypted identifiers across multiple Ontario health administrative databases containing information on all publicly insured, medically necessary hospital and physician services. These included the Discharge Abstract Database (DAD) for chronic conditions coded during hospital admissions; the Ontario Health Insurance Plan (OHIP) for physician billings, including diagnosis codes and procedures; the Registered Persons Database (RPDB) for resident age and sex; and the Continuing Care Reporting System (CCRS) which includes administrative information on LTCH characteristics and patient-level data from the 


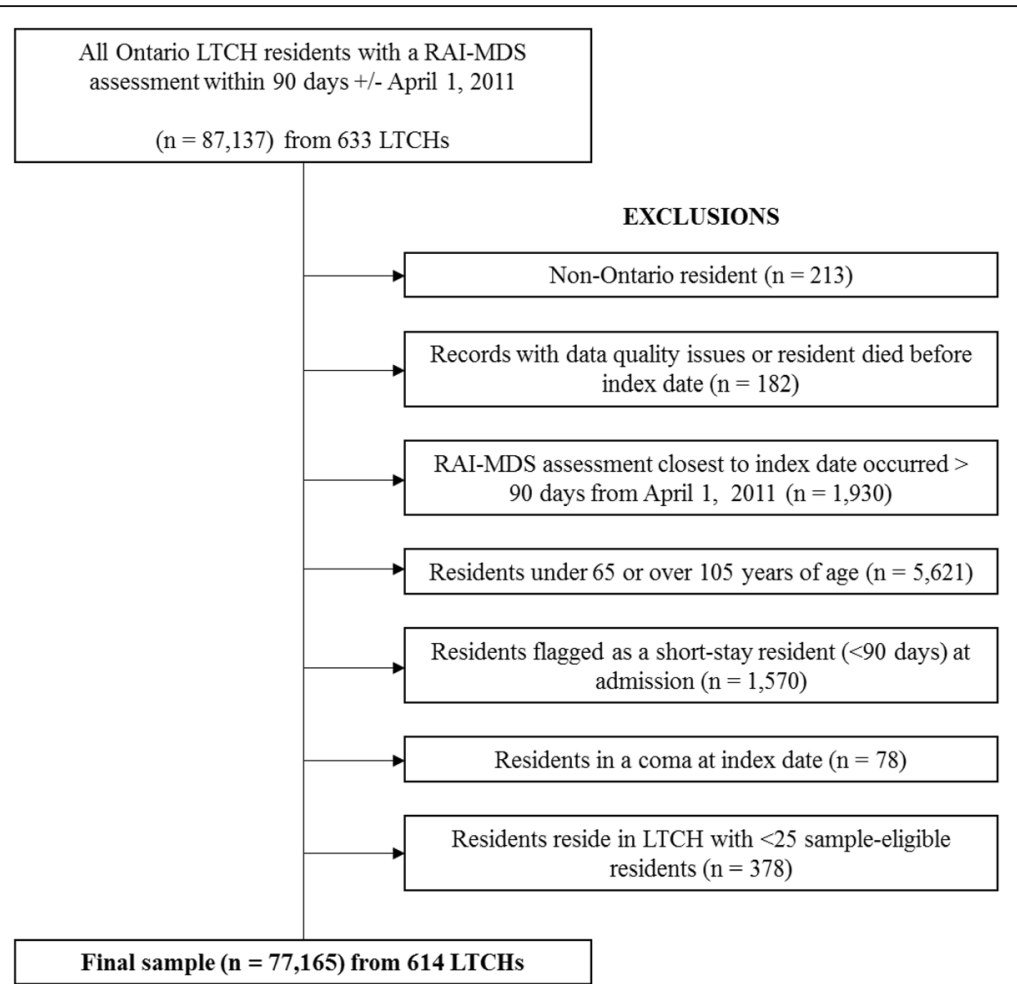

Fig. 1 (Study cohort creation for all Ontario LTCH residents with a RAI-MDS assessment within 90 days +/- April 1, 2011)

Resident Assessment Instrument Minimum Dataset 2.0 (RAI-MDS) assessments carried out in LTCHs [23]. The RAI-MDS is a standardized, multidimensional assessment tool used in LTCHs across Canada, the US and Europe [24]; this study used Ontario RAI-MDS data on resident disability, demographic characteristics, and chronic condition and geriatric syndrome diagnoses. Trained LTCH staff completed the assessments when residents were admitted to $\mathrm{LTCH}$, quarterly, and when there was any significant resident health status change [25].

\section{Outcome}

The primary outcome was resident disability, measured using the ADL long-form score (ADL LFS) from the RAI-MDS assessment closest to the index date. The ADL LFS quantifies resident disability from 0 to 28 based on degree of dependence on others for bed mobility, transfer, locomotion, dressing, eating, toilet use and personal hygiene (see Additional file 1: Table S2). Higher values of ADL LFS indicate higher disability. The ADL LFS is less prone to ceiling effects than more abbreviated disability scales [26], has been validated against standardized measures of disability [27, 28], and is reliable [29]. Although it is an ordinal measure, it was treated as a continuous variable in this study, in keeping with statistical guidelines [30] and precedent in other research [16, 31-33].

\section{Exposures}

Prevalent geriatric syndromes and chronic conditions were the primary exposures of interest. The accrual period for chronic condition diagnoses was five years prior to the index date. Chronic conditions were coded as prevalent if they were identified in hospital or physician billing data as primary or comorbid diagnoses in one inpatient or two outpatient visits within two years of each other [34] or if they were denoted as "active conditions" in RAI-MDS assessments at least once. Geriatric syndromes were coded as present as indicated in residents' RAI-MDS assessment closest to the index date. The full set of 16 chronic conditions and nine geriatric syndromes included, as well as the diagnostic codes used to define them, are listed in Additional file 1: Tables S3 and S4.

\section{Covariates}

Selection of resident and LTCH-level covariates for multivariable models was guided by the Disablement Process Model [20]. Resident-level covariates included age, sex, marital status, pre-admission neighborhood income quintile and the number of days since admission to the LTCH. LTCH-level variables based on aggregate resident characteristics (e.g. proportion of residents restrained) were calculated using all residents in each $\mathrm{LTCH}$ who were assessed within 90 days $(+/-)$ of the index date and were still alive on the index date. 


\section{Statistical analyses}

The frequency and distribution of resident and LTCH characteristics in the sample were determined. Bivariate unadjusted relationships between resident and $\mathrm{LTCH}$ characteristics and disability were assessed in linear regression models. A null model containing only random $\mathrm{LTCH}$ intercepts and no other explanatory variables was run and a likelihood ratio test determined whether there was significant between-LTCH variance in resident disability. Hierarchical multivariable Model 1 contained only random LTCH effects and resident variables, whereas Model 2 contained random LTCH effects, resident and LTCH variables. This model sequence facilitated stepwise calculation of the total proportion of variance in disability explained by variables in each model $\left(R^{2}\right)$, and the proportion of variance in disability that was between LTCHs in the sample $(\rho)$ [35]. To test for multicollinearity of the variables in the multivariable model, the variance inflation factor (VIF) was estimated for each predictor in the reported model (Model 1). The assumption of normally distributed residual errors was also verified. To test whether the effect of chronic diseases and geriatric syndromes on disability were stronger among women, the oldest residents and individuals who were cognitively impaired, we conducted a descriptive analysis of Model 1 stratified by sex, age and cognitive status (cognitively intact or borderline versus cognitive impaired [36]).

\section{Sensitivity analyses}

We re-ran Model 1 with fixed effects instead of random effects for LTCHs to examine whether unmeasured LTCH effects were biasing our findings. Fixed effects account for individual LTCH's effect on variance in residents' disability, without specifying the $\mathrm{LTCH}$ variables responsible, whereas random effects adjust for the overall variation across all LTCHs. If coefficient estimates from the fixed effects version of Model 1 differed significantly from the random effects version, it would suggest that our estimation was biased by relevant LTCH characteristics that we were unable to measure. A linear regression with no random or fixed effects for LTCHs was also run. We also re-ran Model 1 , alternatively removing all geriatric syndromes, all chronic conditions, and all variables except for four geriatric syndromes to test how sensitive effects for each type of exposure was to adjustment for the other. To examine the sensitivity of our findings to coding of chronic conditions, we re-ran Model 1 using chronic condition codes from claims data only, then using chronic condition codes from RAI-MDS data only. Model 2 was re-run excluding residents whose data were from admission assessments to examine whether their inclusion weakened relationships between LTCH characteristics and resident disability. Descriptive analyses were done using SAS version 9.3 [37] and regression modelling was done in STATA.

\section{Results}

Resident and long-term care home characteristics

A total of 77,165 residents from $614 \mathrm{LTCHs}$ were included in the sample and are described in Table 1. The median disability score for all residents in the sample was 18 (IQR: 9, 23); 71.2\% of them were female and their mean age was 84.9 years (SD: 7.5). LTCHs had an average of 126 (SD: 67.3) active beds and the majority of homes in the sample were classified as medium size, forprofit, and located in urban settings (Table 2). There was very little variation in LTCH-level mean disability associated with different levels of the measured LTCH characteristics (Table 2).

\section{Multivariable models of disability in long-term care residents}

The coefficients in Table 3 represent the association of chronic conditions and geriatric syndromes with the 29point ADL LFS measure of disability. Variables with significant positive coefficients (e.g. Parkinson's) are associated with greater disability, whereas variables with significant negative coefficients (e.g. coronary artery disease) are associated with less disability, adjusting for other variables in the table. A one-point increase in ADL LFS is considered the minimum threshold for clinical significance, as it indicates increased dependence in an ADL or dependence in a new ADL, both of which are associated with intensified care needs from LTCH staff [38]. Because LTCH characteristics had small and non-significant effects on disability, estimates from Model 1-which includes random effects for LTCHs but no LTCH characteristics-are reported. Coefficient estimates for all covariates included in Models 1 and 2 can be found in Additional file 1: Table S5. The mean VIF for variables in Model 1 is 1.53 (Range: 1.04-3.69), which falls far below the threshold (VIF $\geq 10$ ) indicative of multicollinearity.

\section{Geriatric syndromes and chronic conditions associated with disability}

Balance impairment, urinary and bowel incontinence, pressure ulcer, severe visual impairment and severe cognitive impairment each had statistically significant independent associations with a minimum 2.5 point increase in disability (Table 3 ). Mild to moderate cognitive impairment, moderate visual impairment and daily or severe daily pain were also positively associated with more disability, but their effects were smaller, ranging from 0.59 to 1.79 (Table 3). Compared to being underweight, having a healthy body mass index (BMI) and being obese were both associated with lower disability; the protective effects of not being underweight were greatest in residents with overweight BMIs.

Compared to geriatric syndromes, chronic conditions had small associations with disability in multivariable 
Table 1 Characteristics of long-term care residents in sample

\begin{tabular}{|c|c|c|c|}
\hline Characteristics & $N$ & $\%$ & $\begin{array}{l}\text { Mean Disability } \\
\text { (SD) }\end{array}$ \\
\hline Full Cohort & 77,165 & 100 & $16.1(8.4)$ \\
\hline \multicolumn{4}{|l|}{ Age (years) } \\
\hline $65-74$ & 7,859 & 10.2 & $15.1(8.0)^{\ddagger}$ \\
\hline $75-84$ & 25,703 & 33.3 & $15.9(8.6)^{\ddagger}$ \\
\hline $85-94$ & 36,676 & 47.5 & $16.2(8.3)^{\ddagger}$ \\
\hline $95+$ & 6,927 & 9.0 & $17.6(7.7)^{\ddagger}$ \\
\hline \multicolumn{4}{|l|}{ Sex } \\
\hline Female & 54,953 & 71.2 & $16.4(8.4)^{\ddagger}$ \\
\hline Male & 22,212 & 28.8 & $15.4(8.5)^{\ddagger}$ \\
\hline \multicolumn{4}{|l|}{ Marital Status } \\
\hline Married & 18,632 & 17.0 & $17.0(8.4)^{\ddagger}$ \\
\hline Widowed & 46,067 & 16.1 & $16.1(8.4)^{\ddagger}$ \\
\hline Never married/Separated/Divorced & 11,299 & 14.8 & $14.8(8.6)^{\ddagger}$ \\
\hline Missing data & 1,167 & 15.7 & $15.7(8.4)^{\ddagger}$ \\
\hline \multicolumn{4}{|l|}{ Pre-LTCH Neighborhood Income Quintile } \\
\hline 1 (low) & 17,671 & 22.9 & $15.4(8.5)^{\ddagger}$ \\
\hline 2 & 13,510 & 17.5 & $16.0(8.4)^{\ddagger}$ \\
\hline 3 & 13,473 & 17.5 & $15.9(8.5)^{\ddagger}$ \\
\hline 4 & 11,790 & 15.3 & $16.4(8.3)^{\ddagger}$ \\
\hline 5 (high) & 10,909 & 14.1 & $16.4(8.4)^{\ddagger}$ \\
\hline Missing data & 9,812 & 12.7 & $17.0(8.4)^{\ddagger}$ \\
\hline \multicolumn{4}{|l|}{ Days in LTCH Prior to Index Date } \\
\hline 0-4 months & 19,202 & 24.9 & $15.3(8.1)^{\ddagger}$ \\
\hline$>4$ months - 12 months & 14,045 & 18.2 & $15.0(8.2)^{\ddagger}$ \\
\hline$>1$ year -2 years & 13,854 & 17.9 & $15.3(8.4)^{\ddagger}$ \\
\hline$>2$ years -3 years & 8,515 & 11.0 & $16.1(8.5)^{\ddagger}$ \\
\hline$>3$ years & 21,549 & 27.9 & $18.0(8.6)^{\ddagger}$ \\
\hline \multicolumn{4}{|l|}{ Prevalent Geriatric Syndromes } \\
\hline Balance impairment & 59,502 & 77.1 & $18.5(7.4)^{\ddagger}$ \\
\hline Bowel incontinence & 37,966 & 49.2 & $21.4(5.7)^{\ddagger}$ \\
\hline \multicolumn{4}{|l|}{ Cognitive status } \\
\hline Intact or borderline intact & 18,426 & 23.9 & $10.9(8.0)^{\ddagger}$ \\
\hline Mild/moderate impairment & 37,204 & 48.2 & $14.8(7.5)^{\ddagger}$ \\
\hline Moderate-severe/severe impairment & 21,535 & 27.9 & $22.7(5.8)^{\ddagger}$ \\
\hline \multicolumn{4}{|l|}{ Hearing impairment } \\
\hline None & 66,718 & 86.5 & $15.9(8.5)^{\ddagger}$ \\
\hline Hearing impaired & 10,269 & 13.3 & $17.6(8.0)^{\ddagger}$ \\
\hline Missing data & 178 & 0.2 & $15.3(8.3)^{\ddagger}$ \\
\hline \multicolumn{4}{|l|}{ Body mass index (BMI) } \\
\hline $\mathrm{BMl}<18.5$ & 6683 & 8.7 & $18.7(7.8)^{\ddagger}$ \\
\hline $18.5 \leq \mathrm{BMI} \leq 25$ & 32,614 & 42.3 & $16.7(8.4)^{\ddagger}$ \\
\hline $25<\mathrm{BMl}<30$ & 22,134 & 28.7 & $15.2(8.6)^{\ddagger}$ \\
\hline $\mathrm{BMI} \geq 30$ & 15,734 & 20.4 & $15.0(8.3)^{\ddagger}$ \\
\hline
\end{tabular}

Table 1 Characteristics of long-term care residents in sample (Continued)

\begin{tabular}{llll}
\hline Pain & & & \\
None & 46,595 & 60.4 & $16.3(8.5)^{\ddagger}$ \\
Less than daily pain & 17,895 & 23.2 & $15.6(8.2)^{\ddagger}$ \\
Daily or severe daily pain & 12,675 & 16.4 & $16.2(8.4)^{\ddagger}$ \\
Pressure ulcer & 4,834 & 6.3 & $22.2(6.0)^{\ddagger}$ \\
Urinary incontinence & 54,922 & 71.2 & $19.1(6.8)^{\ddagger}$ \\
Visual impairment & & & \\
None & 43,701 & 56.6 & $14.4(8.4)^{\ddagger}$ \\
Moderate impairment & 27,264 & 35.3 & $17.5(7.9)^{\ddagger}$ \\
Severe impairment & 6,022 & 7.8 & $22.0(7.2)^{\ddagger}$ \\
Missing & 178 & 0.2 & $15.3(8.3)^{\ddagger}$ \\
Prevalent Chronic Conditions & & & \\
Arthritis & 48,114 & 62.4 & $15.8(8.3)^{\ddagger}$ \\
Asthma & 5,740 & 7.4 & $15.4(8.3)^{\ddagger}$ \\
Cancer & 25,016 & 32.4 & $15.3(8.4)^{\ddagger}$ \\
Kidney disease & 17,124 & 22.2 & $16.1(8.2)$ \\
Coronary artery disease & 29,999 & 38.9 & $15.6(8.4)^{\ddagger}$ \\
Chronic obstructive pulmonary disease & 16,823 & 21.8 & $15.0(8.3)^{\ddagger}$ \\
Dementia & 65,291 & 84.6 & $16.6(8.3)^{\ddagger}$ \\
Diabetes & 24,456 & 31.7 & $16.0(8.3)$ \\
Epilepsy & 5,262 & 6.8 & $18.1(8.3)^{\ddagger}$ \\
Heart failure & 19,430 & 25.2 & $15.9(8.1)^{\ddagger}$ \\
Limb paralysis or amputation & 7,031 & 9.1 & $20.2(6.5)^{\ddagger}$ \\
Mood disorders & 32,389 & 42.0 & $16.4(8.3)^{\ddagger}$ \\
Parkinson's disease & 7,082 & 9.2 & $18.7(7.6)^{\ddagger}$ \\
Peripheral vascular disease & 7,132 & 9.2 & $16.0(8.1)$ \\
Psychiatric conditions other than & 21,288 & 27.6 & $15.1(8.5)^{\ddagger}$ \\
\hline
\end{tabular}

All $p$-values from ANOVAs to test differences in ADL LFS across different levels of each category

${ }^{\dagger} p$-value $<0.01$

${ }^{\ddagger} p$-value $<0.0001$

models (Table 3). Exclusion of geriatric syndromes from the model resulted in increased effect size and statistical significance of chronic condition coefficients, but reduced the model $R^{2}$ from $62.7 \%$ to $11.2 \%$ (see Additional file 1 : Table S6). Having Parkinson's, heart failure, stroke, limb paralysis or amputation, kidney disease, or mood disorder were significantly associated with higher resident disability, however the size of these independent associations were smaller than those of geriatric syndromes, ranging from 0.22 to 1.93 . Asthma, peripheral vascular disease and diabetes were not significantly associated with disability in multivariable models.

Dementia was strongly associated with higher disability in a bivariate model (Table 3), and in a model without 
Table 2 Characteristics of long-term care homes (LTCHs) in sample

\begin{tabular}{|c|c|c|c|}
\hline Characteristic & $\mathrm{N}$ & $\%$ & $\begin{array}{l}\text { Grand Mean (SD) } \\
\text { of homes' ADL } \\
\text { LFS means }\end{array}$ \\
\hline Full Sample & 614 & 100 & $15.7(2.0)$ \\
\hline \multicolumn{4}{|l|}{ LTCH Size (\# beds) } \\
\hline Small $(\leq 64)$ & 128 & 20.8 & $15.4(2.3)$ \\
\hline Medium (65-128) & 248 & 40.4 & $15.5(2.2)$ \\
\hline Large (129-192) & 154 & 25.1 & $15.7(2.2)$ \\
\hline Extra-large ( $\geq 193)$ & 84 & 13.7 & $16.0(2.0)$ \\
\hline \multicolumn{4}{|l|}{ Ownership status } \\
\hline Not-for-profit & 228 & 37.1 & $15.5(2.2)^{*}$ \\
\hline For-profit & 378 & 61.6 & $15.8(2.1)^{*}$ \\
\hline Missing data & 8 & 1.3 & $12.1(2.4)^{*}$ \\
\hline \multicolumn{4}{|l|}{ Location } \\
\hline Rural & 136 & 22.2 & $14.8(2.1)^{*}$ \\
\hline Sub-urban (census agglomerations) & 97 & 15.8 & $14.9(1.92)^{*}$ \\
\hline Urban (census metropolitan areas) & 381 & 62.1 & $16.0(2.1)^{*}$ \\
\hline \multicolumn{4}{|l|}{ Receipt of Rehabilitation Services } \\
\hline $\begin{array}{l}\text { Lowest quartile (Received by } \leq 74.5 \% \\
\text { of residents in home) }\end{array}$ & 153 & 24.9 & $15.3(2.2)^{*}$ \\
\hline $\begin{array}{l}\text { 2nd quartile (Received by }>74.5 \% \text { and } \\
\leq 86.4 \% \text { of residents in home) }\end{array}$ & 154 & 25.1 & $15.3(2.3)^{*}$ \\
\hline $\begin{array}{l}\text { 3rd quartile (Received by }>86.4 \text {, and } \\
\leq 94.1 \% \text { of residents in home) }\end{array}$ & 154 & 25.1 & $15.9(2.2)^{*}$ \\
\hline $\begin{array}{l}\text { Highest quartile (Received by }>94.7 \% \\
\text { of residents in home) }\end{array}$ & 153 & 24.9 & $15.8(2.0)^{*}$ \\
\hline \multicolumn{4}{|l|}{ Restraint use } \\
\hline $\begin{array}{l}\text { Lowest quartile (Homes in which } \\
\leq 6.0 \% \text { residents restrained) }\end{array}$ & 153 & 24.9 & $15.3(2.6)^{*}$ \\
\hline $\begin{array}{l}\text { 2nd quartile (Homes in which }>6.0 \% \\
\text { and } \leq 13.4 \% \text { residents restrained) }\end{array}$ & 154 & 25.1 & $15.2(2.0)^{*}$ \\
\hline $\begin{array}{l}\text { 3rd quartile (Homes in which }>13.4 \% \\
\text { and } \leq 20.6 \% \text { residents restrained) }\end{array}$ & 153 & 24.9 & $15.5(2.1)^{*}$ \\
\hline $\begin{array}{l}\text { Highest quartile (Homes in which } \\
\geq 20.6 \% \text { residents restrained) }\end{array}$ & 154 & 25.1 & $16.4(1.8)^{*}$ \\
\hline \multicolumn{4}{|l|}{ Median ADL of residents in each home ${ }^{\S}$} \\
\hline $\begin{array}{l}\text { Lowest quartile (Homes whose } \\
\text { residents' median ADL LFS } \leq 15 \text { ) }\end{array}$ & 176 & 28.7 & $13.2(1.3)^{*}$ \\
\hline $\begin{array}{l}\text { 2nd quartile (Homes whose residents } \\
\text { median ADL LFS }>15, \leq 17 \text { ) }\end{array}$ & 180 & 29.3 & $15.3(0.9)^{*}$ \\
\hline $\begin{array}{l}\text { 3rd quartile (Homes whose residents } \\
\text { median ADL LFS }>17,<19 \text { ) }\end{array}$ & 103 & 16.8 & $16.2(0.9)^{*}$ \\
\hline $\begin{array}{l}\text { Highest quartile (Homes whose } \\
\text { residents ADL LFS } \geq 19 \text { ) }\end{array}$ & 155 & 25.2 & $18.2(1.3)^{*}$ \\
\hline
\end{tabular}

${ }^{*}$ Significant $(p<0.05)$ difference between levels of categorical variable according to ANOVA

${ }^{5}$ The 614 LTCHs in the sample did not divide into quartiles of even size because of the small range of values for this variable and large number of homes with identical values geriatric syndromes (see Additional file 1: Table S6); this association between dementia and disability is reversed in Model 1, which also adjusted for cognitive status. Although bivariate analyses indicated a negative association between pain and disability, pain was positively associated with disability in fully adjusted analyses (Table 3); exploratory analyses revealed that the change in sign for pain occurred due to adjustment for coexisting geriatric syndromes and number of days since admission (data not shown). A similar reversal of a negative bivariate relationship between heart failure and disability occurred in multivariate models (Table 3), due to adjustment for number of days since admission (data not shown).

\section{Effect modification by residents' sex, age and cognitive status}

As shown in Table 4, the estimated association between chronic conditions and geriatric syndromes with disability in the study sample did not differ in sub-samples of men, women, or individuals aged 74 to 94 . The effect sizes of bowel incontinence, diabetes and cognitive status varied in the youngest (aged 65-74) and oldest (aged 95-plus) residents, however these differences were minor. Only $24 \%$ of residents in the sample did not suffer from moderate to severe cognitive impairment; in these people the association between pressure ulcer and limb paralysis or amputation and disability increased significantly. Conversely, co-existing dementia, visual impairment or bowel incontinence were associated more strongly with disability in those with cognitive impairment. Model estimates for all covariates included in sex-, age- and cognitive status-stratified versions of Models 1 can be found in Additional file 1: Table S7.

\section{Long-term care home characteristics associated with resident disability}

Residents' demographic characteristics and morbidity explained $62.7 \%$ of the variance in disability score. Although a likelihood ratio test indicated that there were statistically significant between-LTCH differences in resident disability $\left(x^{2}=3389.1, p<0.000\right)$, LTCH variables such as intensity of rehabilitation services or ownership type, explained only an additional $2 \%$ of the variance.

\section{Sensitivity analyses}

Sensitivity analyses that removed geriatric syndromes and chronic conditions from multivariable models (see Additional file 1: Table S6) show that geriatric syndromes explained a large amount of the variance in residents' disability, including some of the effects of chronic conditions. In fact, a sensitivity analysis in which only four geriatric syndromes (balance impairment, urinary and bowel incontinence and cognitive impairment) were modelled explained $59.9 \%$ of the variance in disability (see Additional 
Table 3 Geriatric syndromes and chronic conditions associated with disability in long-term care residents

\begin{tabular}{|c|c|c|}
\hline & Unadjusted Bivariate Regressions & Model $1^{\S}$ \\
\hline & Estimate $(95 \% \mathrm{Cl})$ & Estimate $(95 \% \mathrm{Cl})$ \\
\hline \multicolumn{3}{|l|}{ Prevalent Geriatric Syndromes } \\
\hline Balance impairment & $10.48(10.34,10.60)^{\ddagger}$ & $5.69(5.51,5.87)^{\ddagger}$ \\
\hline Bowel incontinence & $10.46(10.37,10.55)^{\ddagger}$ & $4.53(4.38,4.68)^{\ddagger}$ \\
\hline \multicolumn{3}{|l|}{ Cognitive status } \\
\hline Intact/borderline & Reference & Reference \\
\hline Mild/moderate impairment & $3.89(3.76,4.01)^{\ddagger}$ & $1.67(1.55,1.79)^{\ddagger}$ \\
\hline Moderate- severe/severe impairment & $11.73(11.58,11.87)^{\ddagger}$ & $5.27(5.10,5.44)^{\ddagger}$ \\
\hline \multicolumn{3}{|l|}{ Hearing impairment } \\
\hline None & Reference & Reference \\
\hline Hearing impaired & $1.73(1.55,1.90)^{\ddagger}$ & $0.03(-0.08,0.14)$ \\
\hline Missing data & $-0.56(-1.80,0.67)$ & $0.66(-0.15,1.46)$ \\
\hline \multicolumn{3}{|l|}{ Body mass index (BMI) } \\
\hline $\mathrm{BMI}<18.5$ & Reference & Reference \\
\hline $18.5 \leq \mathrm{BMI} \leq 25$ & $-2.02(-2.24,-1.80)^{\ddagger}$ & $-0.54(-0.68,-0.40)^{\ddagger}$ \\
\hline $25<\mathrm{BMl}<30$ & $-3.49(-3.72,-3.26)^{\ddagger}$ & $-0.87(-1.03,-0.72)^{\ddagger}$ \\
\hline $\mathrm{BMI} \geq 30$ & $-3.74(-3.98,-3.50)^{\ddagger}$ & $-0.59(-0.75,-0.43)^{\ddagger}$ \\
\hline \multicolumn{3}{|l|}{ Pain } \\
\hline None & Reference & Reference \\
\hline Less than daily pain & $-0.70(-0.85,-0.56)^{\ddagger}$ & $0.29(0.19,0.39)^{\ddagger}$ \\
\hline Daily or severe daily pain & $-0.12(-0.29,0.04)$ & $0.82(0.70,0.94)^{\ddagger}$ \\
\hline Pressure ulcer & $6.47(6.23,6.72)^{\ddagger}$ & $2.67(2.52,2.82)^{\ddagger}$ \\
\hline Urinary incontinence & $10.50(10.40,10.61)^{\ddagger}$ & $4.19(4.04,4.35)^{\ddagger}$ \\
\hline \multicolumn{3}{|l|}{ Visual impairment } \\
\hline None & Reference & Reference \\
\hline Moderate impairment & $3.09(2.97,3.22)^{\ddagger}$ & $0.68(0.59,0.77)^{\ddagger}$ \\
\hline Severe impairment & $7.62(7.40,7.84)^{\ddagger}$ & $2.49(2.33,2.65)^{\ddagger}$ \\
\hline \multicolumn{3}{|l|}{ Prevalent Chronic Conditions } \\
\hline Arthritis & $-0.66(-0.78,-0.54)^{\ddagger}$ & $0.08(-.0003,0.15)$ \\
\hline Asthma & $-0.71(-0.94,-0.48)^{\ddagger}$ & $0.10(-0.04,0.24)$ \\
\hline Cancer & $-1.23(-1.36,-1.11)^{\ddagger}$ & $-0.12(-0.19,-0.04)^{\dagger}$ \\
\hline Chronic kidney disease & $0.06(0.08,0.20)^{\ddagger}$ & $0.31(0.22,0.40)^{\ddagger}$ \\
\hline Coronary artery disease & $-0.86(-0.98,-0.74)^{\ddagger}$ & $-0.13(-0.21,-0.05)^{\dagger}$ \\
\hline Chronic obstructive pulmonary disease & $-1.39(-1.54,-1.25)^{\ddagger}$ & $-0.07(-0.17,0.02)$ \\
\hline Dementia & $3.39(3.22,3.55)^{\ddagger}$ & $-0.22(-0.35,-0.10)^{\dagger}$ \\
\hline Diabetes & $-0.09(-0.21,0.04)$ & $-0.06(-0.14,0.02)$ \\
\hline Epilepsy & $2.17(1.94,2.41)^{\ddagger}$ & $0.47(0.32,0.61)^{\ddagger}$ \\
\hline Heart failure & $-0.24(-0.38,-0.11)^{\ddagger}$ & $0.36(0.27,0.46)^{\ddagger}$ \\
\hline Limb paralysis or amputation & $4.49(4.29,4.70)^{\ddagger}$ & $1.78(1.63,1.93)^{\ddagger}$ \\
\hline Mood disorder & $0.53(0.41,0.65)^{\ddagger}$ & $0.30(0.22,0.38)^{\ddagger}$ \\
\hline Parkinson's disease & $2.87(2.66,3.07)^{\ddagger}$ & $1.75(1.63,1.87)^{\ddagger}$ \\
\hline Peripheral vascular disease & $-0.14(-0.34,0.07)$ & $0.03(-0.10,0.16)$ \\
\hline Psychiatric conditions other than depression and dementia & $-1.35(-1.48,-1.22)^{\ddagger}$ & $-0.42(-0.50,-0.33)^{\ddagger}$ \\
\hline Stroke & $1.85(1.73,1.98)^{\ddagger}$ & $0.46(0.38,0.55)^{\ddagger}$ \\
\hline
\end{tabular}


Table 3 Geriatric syndromes and chronic conditions associated with disability in long-term care residents (Continued)

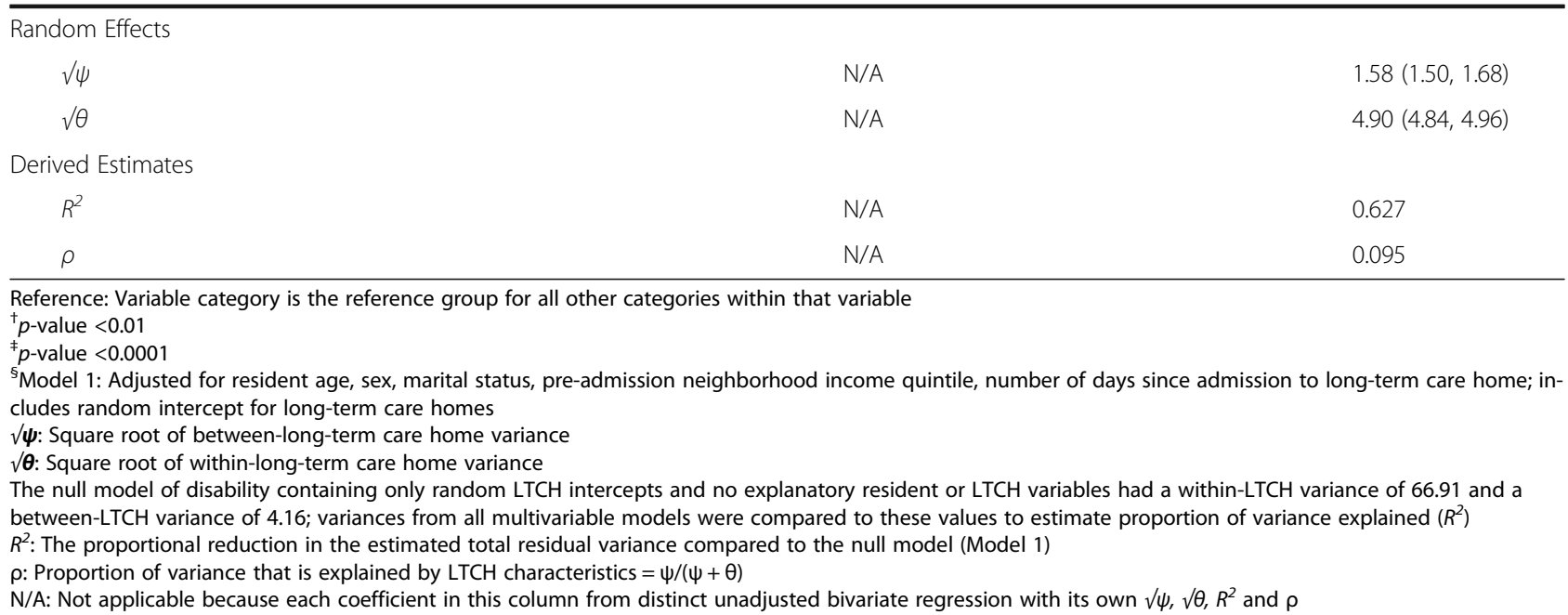

file 1: Table S6). Use of fixed effects to adjust for clustering within LTCHs did not significantly change any model estimates (see Additional file 1: Table S8); proportion of variance in residents' disability attributable to betweenhome differences was $10.3 \%$ in a fixed effects Model 1 versus $9.5 \%$ in the random effects Model 1 . A version of Model 1 without random or fixed effects for LTCHs explained just as much variance in disability as models that accounted for differences between LTCHS (see Additional file 1: Table S8), further verifying the absence of LTCH effects on resident disability. Use of only administrative claims data to code chronic conditions reduced the effects of limb paralysis or amputation and mood disorders, rendering them non-significant, while significantly increasing the effect of stroke (see Additional file 1, Table S9). Use of only RAI-MDS chronic condition codes did not significantly change the effects of any chronic conditions or geriatric syndromes (see Additional file 1: Table S9). Exclusion of the 9,302 residents (12\% of sample) whose data were from admission assessments had no effect on findings from Model 2 (see Additional file 1: Table S9).

\section{Discussion}

Geriatric syndromes explain major differences in disability Geriatric syndromes were much more strongly associated with disability in LTCH residents than were chronic conditions; their removal from Model 1 reduced the $R^{2}$ from $62.7 \%$ to $11.2 \%$ (see Additional file 1: Table S6), showing that they explain approximately $50 \%$ of unique variation in resident disability in this population-based sample. The geriatric syndromes that were most strongly associated with disability were balance impairment, cognitive impairment and urinary and bowel incontinence. Characteristics of LTCHs accounted for less than $2 \%$ of the variance in resident disability once resident characteristics were considered. These findings suggest that residents and their geriatric syndromes-not the LTCHs in which they live-may be appropriate targets of interventions to reduce disability, and that such interventions may need to differ for cognitively impaired versus unimpaired residents.

\section{Mechanisms for geriatric syndrome, chronic condition and LTCH effects}

The Disablement Process Model [20] that guided hypothesis generation and analysis for this study is also instructive in understanding its main findings. The strong association between geriatric syndromes and disability was insensitive to adjustment for coexisting chronic conditions, whereas effects of chronic conditions diminished or were rendered non-significant after adjustment for coexisting geriatric syndromes. A possible mechanism for this finding is that geriatric syndromes mediate some of the effects of chronic conditions on disability. For example, limb paralysis or amputation is strongly associated with disability, but some of this association may be mediated by daily pain. This possible mechanism should be further explored in mediation analyses. An alternative explanation is that geriatric syndromes are proxy measures for disease severity or close proximity to end of life, both of which are associated with disability but not directly measured in our study.

Although there was significant variation in the distribution of LTCH characteristics, descriptive analyses showed that these variations were not associated with corresponding variations in resident disability. This is the likely cause of the lack of explanatory power LTCH characteristics had in models of resident disability. 


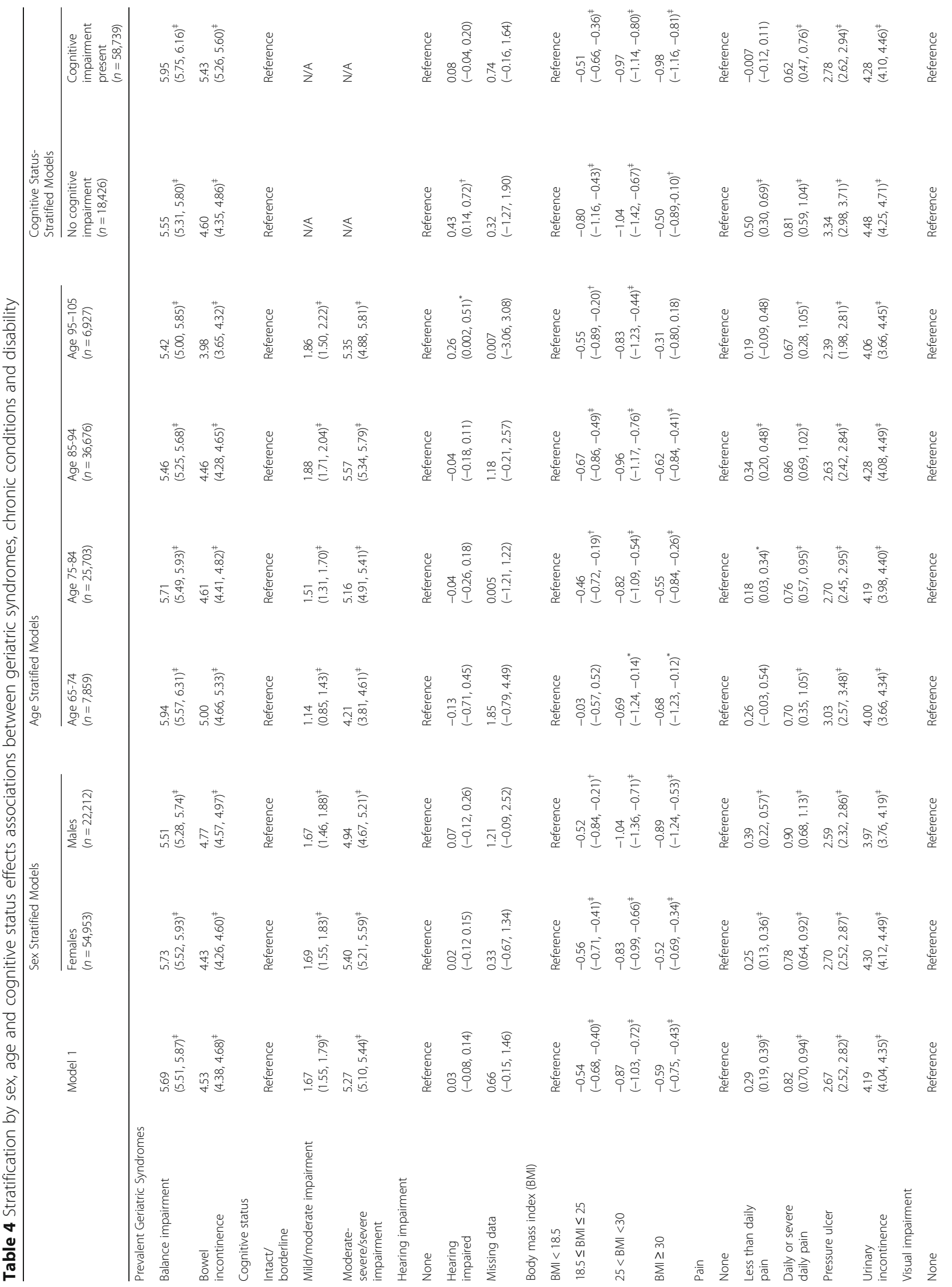




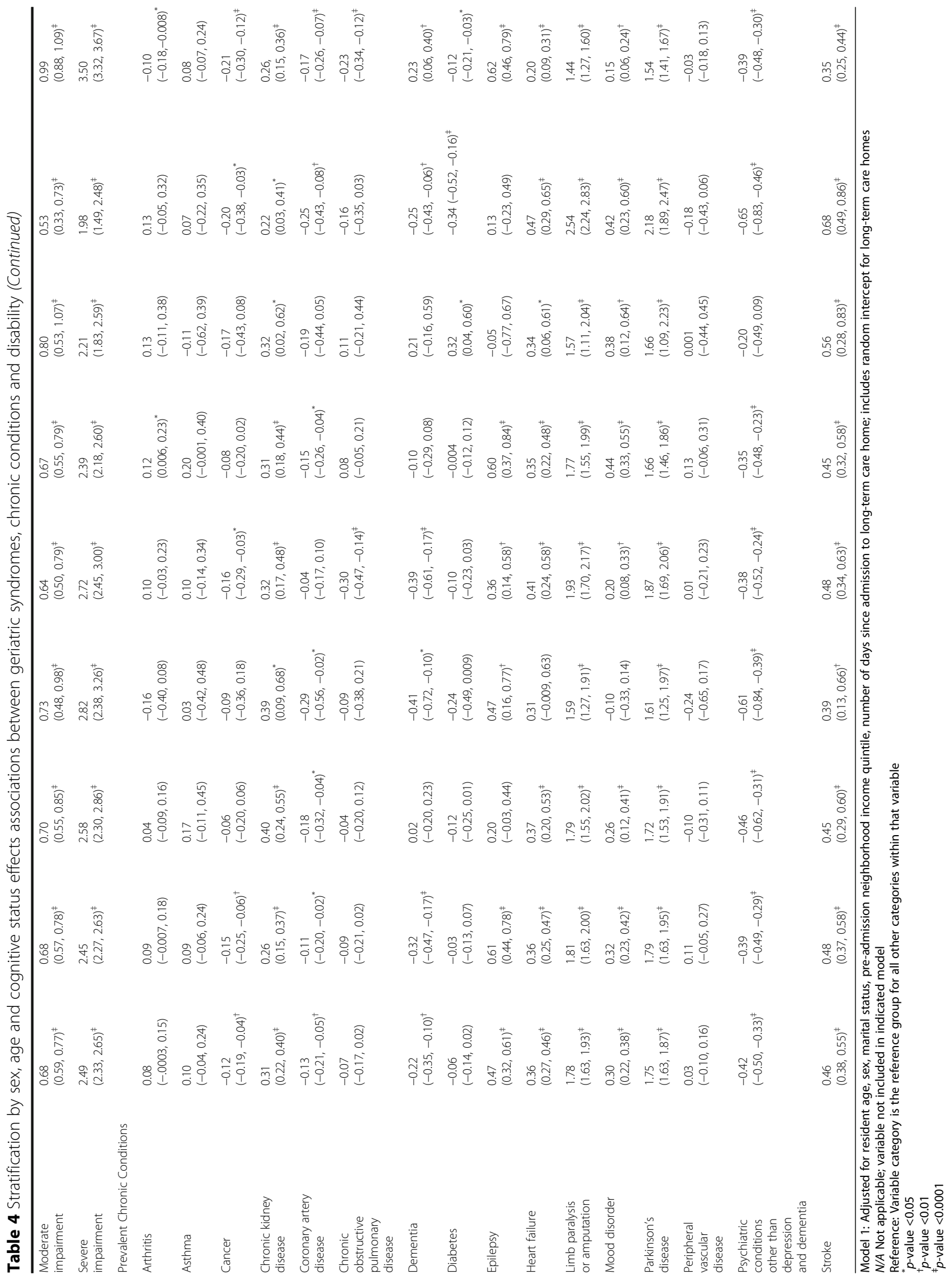




\section{Understanding effect modification by age, sex and cognitive status}

The consistency of chronic condition and geriatric syndrome effects on disability across age and sex strata may represent a nullification of age- and sex- effect modification due to the advanced age and morbidity of LTCH residents. However, it is also possible that females and the oldest old residents in whom chronic conditions and geriatric syndromes were the most strongly associated with disability were under-represented in this cross-sectional sample due to early mortality. We found that some chronic conditions and geriatric syndromes effected residents who were cognitively impaired differently than those who were cognitively intact. Cognitive impairment may exacerbate the effect of prevalent conditions and syndromes due to its impact on older adults' ability to self-care [39], whereas activitylimiting conditions like limb paralysis and Parkinson's may have stronger effects among cognitively intact residents due to their lower overall disability.

\section{Findings in the context of existing evidence}

The dominance of geriatric syndromes over chronic conditions as determinants of health status has recently been demonstrated in community-dwelling older adults [40] but our exploration of this relationship in LTCH residents offers new insight. Other studies of geriatric syndromes' effect on disability in LTCH residents adjusted for the number of chronic conditions that patients had, rather than examining the effects of specific chronic conditions alongside specific geriatric syndromes $[17,18,33,41]$. Our inclusion of specific chronic conditions in multivariable models revealed that effects of some chronic conditions (e.g. dementia) were particularly sensitive to adjustment for coexisting geriatric syndromes in models of disability.

While we found a stronger effect of pressure ulcer on disability in cognitively intact residents, the effect of bowel incontinence and visual impairment on disability was significantly stronger in cognitively impaired residents in our sample. These mixed results align with existing evidence, some of which supports exacerbated effects of chronic conditions among cognitively impaired older adults [15] and some of which shows worse effects among cognitively intact older adults [32]. Compared to being underweight (BMI <18.5), having an overweight BMI (BMI 25-30) was associated with the lowest level of disability in multivariable models. These findings mirror findings regarding the association of BMI with mortality: results of a recent meta-analysis of more than 30.3 million people in 230 cohort studies found that the lowest mortality was observed among those with a BMI of approximately 25 [42]. Similar to the association between underweight BMI and increased mortality [42], the relationship between $\mathrm{BMI}<18.5$ and disability in this study may be confounded by low body weight resulting from chronic disease [43]. Our adjustment for 16 chronic conditions and nine geriatric syndromes addresses much of this potential confounding, however longitudinal studies of this association are needed.

The proportion of variance in resident disability $(<2 \%)$ explained by LTCH characteristics in this sample is smaller than the $8-25 \%$ variance in ADL-LFS found by Phillips et al. in their studies of 1,334 American LTCHs [17, 41]. We hypothesize that this difference occurred because we adjusted for significantly more chronic conditions and geriatric syndromes than Phillips et al., and explained a larger proportion of total model variance $\left(R^{2}=64.2 \%\right)$ than Phillips et al. achieved $\left(R^{2}=18 \%\right)$ [41], thus reducing variance attributed LTCHs. The weak effects of specific LTCH variables in our study is consistent with another study of LTCH effects on disablement in LTCH residents [33], as well as equivocal evidence for the relationship between LTCH characteristics and other resident health outcomes [12, 44].

\section{Strengths}

This study used health administrative data in a singlepayer health care system to study the relationships between resident morbidity, LTCH characteristics and disability in a large, representative sample with adjustment for multiple confounders. Our large sample size also allowed for examination of effects among strata of putative effect modifiers that were larger than many studies' main samples. In contrast with most studies in $\mathrm{LTCH}$ residents that use either validated administrative claims algorithms or RAI-MDS active diagnoses to identify chronic conditions, we combined these measures and tested the sensitivity of our findings to this choice. Although claims data tend to be more sensitive for the detection of some diagnoses (e.g. heart failure, arthritis), RAI-MDS assessments are more sensitive to other conditions (e.g. Alzheimer's, hip fracture) [45]. Our findings suggest that using combined chronic condition measures from both data sources yields findings that are fairly comparable to those generated using only one. Existing studies that examine the relationship between morbidity and disability either do not include specific chronic conditions in models $[17,18,33,41]$, or do not examine the sensitivity of model estimates to adjustment for geriatric syndromes [16]. By doing both, we produced robust empirical findings while also testing a theoretical extension of a heavily used conceptual framework. The absence of multicollinearity in our large multivariable models supports future use of the Disablement Process Model [20] as a guide to identify conceptually distinct variables in disability research. 


\section{Limitations}

Due to the cross-sectional nature of our study, we cannot make causal inferences regarding the associations that we report. Our sample also captures residents at different stages of their LTCH journey; because the magnitude of association between specific chronic conditions and geriatric syndromes and disability may change over time since admission, we adjusted multivariable models for the duration of time residents had been in their LTCH. There were several geriatric syndromes that were not included in this study for conceptual and methodological reasons. Extant conceptualizations and administrative data measures of frailty include both the outcome (disability) and the exposures (symptoms, signs, disease) of interest in this study $[46,47]$, therefore frailty was not included in multivariable models despite being a well-known geriatric syndrome. Sarcopenia-defined as low muscle mass and either reduced strength or physical performance [48] - was not measured in this study, however we measured BMI, which is an excellent proxy for sarcopenia in age-adjusted models among older adults [49]. Polypharmacy is another geriatric syndrome that was excluded from this analysis because it is a marker of underlying health status that exists along the causal pathway between the exposures of interest (chronic conditions and geriatric syndromes) and health outcomes (disability) in this study [50]. Delirium and falls are important geriatric syndromes that were excluded from this cross-sectional study due to their acute nature and the longitudinal data required to examine their effects; however, our inclusion of geriatric syndromes associated with delirium and falls (i.e. cognitive status and balance impairment) likely accounted for much of the variance in disability associated with these acute health events.

We did not have data on numerous LTCH characteristics potentially associated with residents' disability (e.g. staffing levels [10] and immunization rates [51]), therefore interpretation of the effects for the few LTCH variables we did measure (e.g. for-profit ownership) should be tempered by the knowledge that these variables may be absorbing variance from unmeasured variables. However, we did replicate our findings in models with fixed effects for LTCHs and thus verified that they were not due our inability to measure relevant LTCH characteristics in our random effects models.

\section{Conclusions}

Our findings show that geriatric syndromes explain more variation in resident disability than chronic conditions and features of LTCHs combined. These findings suggest that residents and their geriatric syndromes-not the LTCHs in which they live-may be the appropriate target of interventions to reduce disability, and that such interventions may need to differ for cognitively impaired versus unimpaired residents. These associations should be further explored in longitudinal studies.

\section{Additional file}

\begin{abstract}
Additional file 1: Table S1. (Disablement Process Model definitions and examples); Table S2. (Items and Possible Responses in the RAI-MDS ADL Long Form Scale); Table S3. (Chronic Conditions and Diagnostic Criteria Used to Identify them in Claims and Health Assessment Databases); Table S4. (Geriatric Syndromes and Diagnostic Criteria Used to Identify them in the CCRS Database); Table S5. (All Variable Coefficient Estimates from Models 1 and 2); Table S6. (Model 1 Excluding Chronic Conditions, Geriatric Syndromes); Table S7. (All Variable Coefficient Estimates from Stratified Versions of Model 1); Table S8. (Sensitivity of Model 1 Findings to Unmeasured LTCH Variables and Lack of adjustment for Long-Term Care Homes); Table S9. (Sensitivity of Model 1 Findings to Coding of Chronic Conditions); Table S10. (Sensitivity of Model 2 Findings to Exclusion of Admission Assessments). (DOCX 87 kb)
\end{abstract}

\section{Abbreviations}

ADL LFS: Activities of daily living long-form score; ADLs: Activities of daily living; BMI: Body Mass Index; CCRS: Continuing care reporting system; DAD: Discharge abstract database; ICES: Institute for clinical evaluative sciences; LTCH: Long-term care home; MOHLTC: Ministry of health and long-term care; OHIP: Ontario health insurance plan; RAI-MDS: Resident assessment instrument minimum dataset 2.0; RPDB: Registered persons database; VIF: Variance inflation factor

\section{Acknowledgements}

The authors acknowledge Ms. Alice Newman at ICES for her meticulous work creating the dataset for this study.

\section{Funding}

This work was supported by a research grant from the Ontario Ministry of Health and Long Term Care (MOHLTC) to the Health System Performance Research Network (Grant \# 06034) and by the Institute for Clinical Evaluative Sciences (ICES), which is funded by annual grants from the MOHLTC. Natasha Lane was supported by a Vanier Canada Graduate Scholarship from the Canadian Institutes of Health Research. Cynthia Boyd was supported by the Paul Beeson Career Development Award (NIA K23 AG032910), The John A. Hartford Foundation, Atlantic Philanthropies, and the Starr Foundation. The corresponding author had full access to all the data in the study and had final responsibility for the decision to submit for publication. Conclusions reported in this paper are those of the authors and are independent from the funding sources. No endorsement by the MOHLTC or ICES is intended or should be inferred. The funding sources for this study had no role in study design, data collection, analysis, or interpretation of data, nor in the writing of the manuscript.

\section{Availability of data and materials}

The individual-level data underlying this study are based on records generated from the administration of Ontario's publicly funded health system. ICES has a special designation under Ontario's Personal Health Information Protection Act to use these data in studies that evaluate health care delivery and outcomes. This designation is granted by the Information and Privacy Commissioner of Ontario, and is contingent on a triennial review and ongoing oversight of the privacy practices at ICES. A variety of measures are deployed to protect the personal health information entrusted to ICES and, under the Personal Health Information Protection Act (Ontario Regulation 329/04), the underlying data are legally not allowed for public repository.

\section{Authors' contributions}

NEL conceived and designed the study, accessed the data and performed the data analysis and interpretation, wrote the first draft and contributed to critical revisions of the manuscript. WPW, CMB and TAS contributed to study and analysis design, data interpretation and critical revisions of the manuscript. All authors read and approved the final manuscript. 


\section{Competing interests}

The authors declare that they have no competing interests.

\section{Consent for publication}

Not applicable.

\section{Ethics approval and consent to participate}

This study received ethics approval from the University of Toronto Office of Research Ethics (Protocol Reference \# 31821) and the Sunnybrook Health Sciences Research Ethics Board in Toronto, Ontario, Canada. The individual-level data underlying this study are based on records generated from the administration of Ontario's publicly funded health system and housed at the Institute of Clinical Evaluative Sciences (ICES). ICES has been specially designated by the Information and Privacy Commissioner of Ontario under Ontario's Personal Health Information Protection Act to use these data in studies that evaluate health care delivery and outcomes without requiring informed consent from each individual. Informed consent was therefore not obtained from each individual from whom data was used in this study.

\section{Author details}

${ }^{1}$ Institute of Health Policy, Management and Evaluation, University of Toronto, 155 College St, 4th Floor, Toronto, ON M5T 3M6, Canada. ${ }^{2}$ Institute for Clinical Evaluative Sciences, G1 06 - 2075 Bayview Avenue, Toronto, ON M4N 3M5, Canada. ${ }^{3}$ Toronto Rehabilitation Institute, 550 University Avenue, 3rd Floor, Toronto, ON M5G 2A2, Canada. ${ }^{4}$ Johns Hopkins School of Medicine, 1830 E. Monument St, Baltimore, MD 21287, USA. ${ }^{5}$ Johns Hopkins Bloomberg School of Public Health, 615 North Wolfe Street, Baltimore, MD 21205, USA. ${ }^{6}$ Johns Hopkins Center on Aging and Health, 2024 E. Monument St, Suite 2-700, Baltimore, MD 21205, USA. 'D Dartmouth Institute for Health Policy \& Clinical Practice, Geisel School of Medicine at Dartmouth, Hanover $\mathrm{NH}$ 03755, USA.

Received: 13 October 2016 Accepted: 7 February 2017 Published online: 10 February 2017

\section{References}

1. Canadian Institute for Health Information. When a nursing home is home: how do Canadian nursing homes measure up on quality. Toronto: Canadian Institute of Health Information 2013. https://secure.cihi.ca/free_products/ CCRS_QualityinLongTermCare_EN.pdf. Accessed 12 Oct 2016.

2. Katz PR. An international perspective on long term care: focus on nursing homes. J Am Med Dir Assoc. 2011;12(7):487-492.e481.

3. Dutcher SK, Rattinger GB, Langenberg P, Chhabra PT, Liu X, Rosenberg PB, Leoutsakos JM, Simoni-Wastila L, Walker LD, Franey CS, et al. Effect of medications on physical function and cognition in nursing home residents with dementia. J Am Geriatr Soc. 2014;62(6):1046-55.

4. Andersen CK, Wittrup-Jensen KU, Lolk A, Andersen K, Kragh-Sorensen P. Ability to perform activities of daily living is the main factor affecting quality of life in patients with dementia. Health Qual Life Outcomes. 2004;2:52.

5. Kruse RL, Petroski GF, Mehr DR, Banaszak-Holl J, Intrator O. Activity of daily living trajectories surrounding acute hospitalization of long-stay nursing home residents. J Am Geriatr Soc. 2013;61(11):1909-18.

6. de Meijer CA, Koopmanschap MA, Koolman XH, van Doorslaer EK. The role of disability in explaining long-term care utilization. Med Care. 2009;47(11): 1156-63.

7. Thomas JM, Cooney Jr LM, Fried TR. Systematic review: Health-related characteristics of elderly hospitalized adults and nursing home residents associated with short-term mortality. J Am Geriatr Soc. 2013;61(6):902-11.

8. Yeh KP, Lin MH, Liu LK, Chen LY, Peng LN, Chen LK. Functional decline and mortality in long-term care settings: Static and dynamic approach. J Clin Geron Geriatr. 2014;5(1):13-7.

9. Werner RM, Konetzka RT, Polsky D. The effect of pay-for-performance in nursing homes: evidence from state Medicaid programs. Health Serv Res. 2013:48(4):1393-414.

10. Bellows NM, Halpin HA. MDS-based state medicaid reimbursement and the ADL-decline quality indicator. Gerontologist. 2008;48(3):324-9.

11. Your Health System. http://yourhealthsystem.cihi.ca/hsp/indepth?lang=en. Accessed 12 Oct 2016.

12. Zimmerman $\mathrm{S}$, Anderson WL, Brode $\mathrm{S}$, Jonas $\mathrm{D}$, Lux L, Beeber AS, Watson LC, Viswanathan M, Lohr KN, Sloane PD. Systematic review: Effective characteristics of nursing homes and other residential long-term care settings for people with dementia. J Am Geriatr Soc. 2013;61(8):1399-409.

13. Piernik-Yoder B, Ketchum N. Rehabilitation outcomes of stroke patients with and without diabetes. Arch Phys Med Rehabil. 2013;94(8):1508-12.

14. Carrière I, Gutierrez LA, Pérès K, Berr C, Barberger-Gateau P, Ritchie K, Ancelin ML. Late life depression and incident activity limitations: Influence of gender and symptom severity. J Affect Disord. 2011;133(1-2):42-50.

15. Fultz NH, Ofstedal MB, Herzog AR, Wallace RB. Additive and interactive effects of comorbid physical and mental conditions on functional health. J Aging Health. 2003;15(3):465-81.

16. Fedecostante M, Dell'Aquila G, Eusebi P, Volpato S, Zuliani G, Abete P, Lattanzio F, Cherubini A. Predictors of Functional Changes in Italian Nursing Home Residents: The U.L.IS.S.E. Study. J Am Med Dir Assoc. 2015;17(4):306-11.

17. Phillips CD, Chen M, Sherman M. To what degree does provider performance affect a quality indicator? The case of nursing homes and ADL change. Gerontologist. 2008;48(3):330-7.

18. Chen LY, Liu LK, Liu CL, Peng LN, Lin MH, Chen LK, Lan CF, Chang PL. Predicting Functional Decline of Older Men Living in Veteran Homes by Minimum Data Set: Implications for Disability Prevention Programs in Long Term Care Settings. J Am Med Dir Assoc. 2013;14(4):309.e309-13.

19. Frytak JR, Kane RA, Finch MD, Kane RL, Maude-Griffin R. Outcome trajectories for assisted living and nursing facility residents in Oregon. Health Serv Res. 2001;36(1 Pt 1):91-111.

20. Verbrugge LM, Jette AM. The disablement process. Soc Sci Med. 1994;38(1):1-14.

21. Kernick D. A theoretical framework for multimorbidity: From complicated to chaotic. Brit J Gen Prac. 2012;62(602):e659-62.

22. Chen YH, Ho YL, Huang HC, Wu HW, Lee CY, Hsu TP, Cheng CL, Chen MF. Assessment of the clinical outcomes and cost-effectiveness of the management of systolic heart failure in Chinese patients using a homebased intervention. J Int Med Res. 2010;38(1):242-52.

23. Hirdes JP, Poss JW, Caldarelli H, Fries BE, Morris JN, Teare GF, Reidel K, Jutan N. An evaluation of data quality in Canada's continuing care reporting system (CCRS): Secondary analyses of Ontario data submitted between 1996 and 2011. BMC Med Inform Decis. 2013;13(1):27.

24. Hirdes JP, Ljunggren G, Morris JN, Frijters DH, Finne Soveri H, Gray L, Björkgren M, Gilgen R. Reliability of the interRAl suite of assessment instruments: A 12-country study of an integrated health information system. BMC Health Serv Res. 2008;8:227.

25. Hirdes JP, Mitchell L, Maxwell CJ, White N. Beyond the 'iron lungs of gerontology': Using evidence to shape the future of nursing homes in Canada. Can J Aging. 2011;30(3):371-90.

26. Neuman MD, Silber JH, Magaziner JS, Passarella MA, Mehta S, Werner RM. Survival and functional outcomes after hip fracture among nursing home residents. JAMA Intern Med. 2014;174(8):1273-80.

27. Frederiksen $K$, Tariot P, De Jonghe E. Minimum Data Set Plus (MDS+) scores compared with scores from five rating scales. J Am Geriatr Soc. 1996;44(3):305-9.

28. Lawton MP, Casten R, Parmelee PA, Van Haitsma K, Corn J, Kleban MH. Psychometric characteristics of the minimum data set II: validity. J Am Geriatr Soc. 1998;46(6):736-44.

29. Morris JN, Fries BE, Morris SA. Scaling ADLs within the MDS. J Gerontol ABiol. 1999;54(11):M546-553.

30. Rhemtulla M, Brosseau-Liard PE, Savalei V. When can categorical variables be treated as continuous? A comparison of robust continuous and categorical SEM estimation methods under suboptimal conditions. Psychol Methods. 2012;17(3):354-73.

31. Wolinsky FD, Armbrecht ES, Wyrwich KW. Rethinking functional limitation pathways. Gerontologist. 2000;40(2):137-46.

32. Wang J, Chang LH, Eberly LE, Virnig BA, Kane RL. Cognition moderates the relationship between facility characteristics, personal impairments, and nursing home residents' activities of daily living. J Am Geriatr Soc. 2010;58(12):2275-83

33. Wang J, Kane RL, Eberly LE, Virnig BA, Chang LH. The effects of resident and nursing home characteristics on activities of daily living. J Gerontol A-Biol. 2009;64(4):473-80.

34. Koné Pefoyo AJ, Bronskill SE, Gruneir A, Calzavara A, Thavorn K, Petrosyan Y, Maxwell CJ, Bai YQ, Wodchis WP. The increasing burden and complexity of multimorbidity. BMC Pub Health. 2015;15:1-11.

35. Rabe-Hesketh S, Skronda A. Multilevel and Longitudinal Modeling Using Stata, vol. Volume I: Continuous Responses. 3rd ed. Texas: Stata Press; 2012. College Station. 
36. Morris JN, Fries BE, Mehr DR, Hawes C, Phillips C, Mor V, Lipsitz LA. MDS Cognitive Performance Scale. J Gerontol. 1994;49(4):M174-182.

37. SAS. Cary: SAS Institute; 2012.

38. Carpenter Gl, Hastie CL, Morris JN, Fries BE, Ankri J. Measuring change in activities of daily living in nursing home residents with moderate to severe cognitive impairment. BMC Geriatr. 2006;6:7.

39. Feil DG, Zhu CW, Sultzer DL. The relationship between cognitive impairment and diabetes self-management in a population-based community sample of older adults with Type 2 diabetes. J Behav Med. 2012;35(2):190-9.

40. Koroukian SM, Schiltz N, Warner DF, Sun J, Bakaki PM, Smyth KA, Stange KC, Given CW. Combinations of Chronic Conditions, Functional Limitations, and Geriatric Syndromes that Predict Health Outcomes. J Gen Intern Med. 2016; 31(6):630-7.

41. Phillips CD, Shen R, Chen M, Sherman M. Evaluating nursing home performance indicators: An illustration exploring the impact of facilities on ADL change. Gerontologist. 2007:47(5):683-9.

42. Aune D, Sen A, Prasad M, Norat T, Janszky I, Tonstad S, Romundstad P, Vatten LJ. BMI and all cause mortality: systematic review and non-linear dose-response meta-analysis of 230 cohort studies with 3.74 million deaths among 30.3 million participants. BMJ. 2016;353:12156.

43. Veronese N, Li Y, Manson JE, Willett WC, Fontana L, Hu FB. Combined associations of body weight and lifestyle factors with all cause and cause specific mortality in men and women: prospective cohort study. BMJ. 2016;355:i5855.

44. Comondore VR, Devereaux PJ, Zhou Q, Stone SB, Busse JW, Ravindran NC, Burns KE, Haines T, Stringer B, Cook DJ, et al. Quality of care in for-profit and not-for-profit nursing homes: Systematic review and meta-analysis. BMJ. 2009;339(7717):381-4.

45. Lix LM, Yan L, Blackburn D, Hu N, Schneider-Lindner V, Teare GF. Validity of the RAI-MDS for ascertaining diabetes and comorbid conditions in longterm care facility residents. BMC Health Serv Res. 2014;14:17.

46. Campitelli MA, Bronskill SE, Hogan DB, Diong C, Amuah JE, Gill S, Seitz D, Thavorn K, Wodchis WP, Maxwell CJ. The prevalence and health consequences of frailty in a population-based older home care cohort: a comparison of different measures. BMC Geriatr. 2016;16(1):133.

47. Armstrong JJ, Stolee P, Hirdes JP. Examining three frailty conceptualizations in their ability to predict negative outcomes for home-care clients. 2010 39(6):755-8.

48. Cruz-Jentoft AJ, Baeyens JP, Bauer JM, Boirie Y, Cederholm T, Landi F, Martin FC, Michel J-P, Rolland Y, Schneider SM, et al. Sarcopenia: European consensus on definition and diagnosis: Report of the European Working Group on Sarcopenia in Older People. Age Ageing. 2010;39(4):412-23.

49. Goodman MJ, Ghate SR, Mavros P, Sen S, Marcus RL, Joy E, Brixner DI. Development of a practical screening tool to predict low muscle mass using NHANES 1999-2004. J Cachex, Sarcopenia and Muscle. 2013;4(3):187-97.

50. Fried TR, O'Leary J, Towle V, Goldstein MK, Trentalange M, Martin DK. Health Outcomes Associated with Polypharmacy in Community-Dwelling Older Adults: A Systematic Review. J Am Geriatr Soc. 2014;62(12):2261-72.

51. Barker WH, Borisute $H$, Cox C. A study of the impact of influenza on the functional status of frail older people. Arch Intern Med. 1998;158(6):645-50.

\section{Submit your next manuscript to BioMed Central and we will help you at every step:}

- We accept pre-submission inquiries

- Our selector tool helps you to find the most relevant journal

- We provide round the clock customer support

- Convenient online submission

- Thorough peer review

- Inclusion in PubMed and all major indexing services

- Maximum visibility for your research

Submit your manuscript at www.biomedcentral.com/submit

) Biomed Central 